\title{
Características hidrogeomorfométricas da microbacia do rio Águas Claras,
}

\section{Amazônia Ocidental, Brasil}

\author{
Hydrogeomorphometric characteristics of the Águas Claras river microbasin, Western Amazon, \\ Brazil
}

Características hidrogeomorfométricas de la microcuenca de Águas Claras, Amazonia Occidental, Brasil

\author{
Anderson Assis dos Santos \\ ORCID: https://orcid.org/0000-0003-0607-2526 \\ Universidade Federal do Amazonas, Brasil \\ E-mail: andersonassis06@gmail.com \\ Eduarda Costa da Silva \\ ORCID: https://orcid.org/0000-0002-2771-5968 \\ Universidade Federal do Amazonas, Brasil \\ E-mail: eduardacdsilva@gmail.com \\ Luane Andrade Palmela Cardoso \\ ORCID: https://orcid.org/0000-0002-6478-580X \\ Universidade Federal do Amazonas, Brasil \\ E-mail: cardoso.luane@gmail.com \\ Weslley Mesquita Praia \\ ORCID: https://orcid.org/0000-0001-7985-1577 \\ Universidade Federal do Amazonas, Brasil \\ E-mail: weslleymesquitapraia@gmail.com \\ Francisco Adilson dos Santos Hara \\ ORCID: https://orcid.org/0000-0002-3215-953X \\ Universidade Federal do Amazonas, Brasil \\ E-mail: fhara@ufam.edu.br \\ Wanderson Cleiton Schmidt Cavalheiro \\ ORCID: https://orcid.org/0000-0003-1356-8511 \\ Cavalheiro Engenharia Rural e Empresarial Ltda, Brasil \\ E-mail: engflo.ro@gmail.com \\ Jhony Vendruscolo \\ ORCID: https://orcid.org/0000-0003-3043-0581 \\ Universidade Federal do Amazonas, Brasil \\ E-mail: jhonyvendruscolo@gmail.com
}

\begin{abstract}
Resumo
As informações sobre as características da paisagem são essenciais para o planejamento e gestão dos recursos naturais. Portanto, o objetivo do presente trabalho foi caracterizar a paisagem da microbacia do rio Águas Claras. As informações foram adquiridas por meio de Sensoriamento Remoto, utilizando os softwares QGIS 2.10.1, Google Earth e TrackMaker Free, imagens altimétricas do satélite ALOS, e dados da literatura. A microbacia do rio Águas Claras tem área de 39,27 km², perímetro de 43,25 km, forma alongada, baixa suscetibilidade a inundações, altitudes de 227 a 476 m, predomínio de relevo suave ondulado, 87,32\% da área com baixa influência a propagação de incêndio e apta a extremamente apta a mecanização agrícola, rede de drenagem de $107,14 \mathrm{~km}$, padrão dendrítico de $6^{\mathrm{a}}$ ordem, alta densidade de nascentes, alta densidade de drenagem, coeficiente de manutenção de $366,5 \mathrm{~m}^{2} \mathrm{~m}^{-1}$, índice de sinuosidade de $32,55 \%$ e tempo de concentração de 4,06 h. A microbacia tem elevado potencial para o desenvolvimento de atividades agropecuárias, contudo, recomenda-se a adoção de práticas de manejo do solo e da água para mitigar os impactos nos recursos naturais. É necessário complementar as informações com dados espaciais de cobertura do solo, para delimitar adequadamente as áreas prioritárias para manutenção e/ou recomposição da vegetação nativa.
\end{abstract}

Palavras-chave: Geotecnologias; Recursos naturais; Planejamento e gestão ambiental.

\section{Abstract}

Information on landscape characteristics is essential for planning and managing natural resources. Therefore, the objective of the present work was to characterize the landscape of the Águas Claras river microbasin. The information was acquired through Remote Sensing, using the QGIS 2.10.1, Google Earth and TrackMaker Free software, 
altimetric images from the ALOS satellite, and data from the literature. The microbasin of the Águas Claras river has an area of $39.27 \mathrm{~km}^{2}$, a perimeter of $43.25 \mathrm{~km}$, elongated shape, low susceptibility to flooding, altitudes from 227 to $476 \mathrm{~m}$, predominance of wavy smooth relief, $87.32 \%$ of the area with low influences the spread of fire and is apt to be extremely apt for agricultural mechanization, drainage network of $107.14 \mathrm{~km}$, dendritic pattern of 6th order, high density of springs, high drainage density, maintenance coefficient of $366.5 \mathrm{~m}^{2} \mathrm{~m}^{-1}$, sinuosity index of $32.55 \%$ and concentration time of $4.06 \mathrm{~h}$. The microbasin has a high potential for the development of agricultural activities, however, it is recommended to adopt soil and water management practices to mitigate the impacts on natural resources. It is necessary to complement the information with spatial data on land cover, to properly delimit priority areas for maintenance and / or restoration of native vegetation.

Keywords: Geotechnologies; Natural resources; Environmental planning and management.

\section{Resumen}

La información sobre las características del paisaje es fundamental para la planificación y gestión de los recursos naturales. Por tanto, el objetivo del presente trabajo fue caracterizar el paisaje de la microcuenca del río Águas Claras. La información se adquirió mediante Teledetección, utilizando el software QGIS 2.10.1, Google Earth y TrackMaker Free, imágenes altimétricas del satélite ALOS y datos de la literatura. La microcuenca del río Águas Claras tiene un área de $39.27 \mathrm{~km}^{2}$, un perímetro de $43.25 \mathrm{~km}$, forma alargada, baja susceptibilidad a inundaciones, altitudes de 227 a $476 \mathrm{~m}$, predominio de relieve ondulado suave, $87.32 \%$ del área con baja influye en la propagación del fuego y es muy apto para la mecanización agrícola, red de drenaje de $107,14 \mathrm{~km}$, patrón dendrítico de $6^{\circ}$ orden, alta densidad de manantiales, alta densidad de drenaje, coeficiente de mantenimiento de $366,5 \mathrm{~m}^{2} \mathrm{~m}^{-1}$, índice de sinuosidad de $32,55 \%$ y tiempo de concentración de $4.06 \mathrm{~h}$. La microcuenca tiene un alto potencial para el desarrollo de actividades agrícolas, sin embargo, se recomienda adoptar prácticas de manejo de suelos y aguas para mitigar los impactos sobre los recursos naturales. Es necesario complementar la información con datos espaciales de cobertura terrestre, para delimitar adecuadamente las áreas prioritarias para el mantenimiento y/o restauración de la vegetación nativa.

Palabras clave: Geotecnologías; Recursos naturales; Planificación y gestión ambiental.

\section{Introdução}

A bacia hidrográfica é a unidade de gestão mais adequada para assegurar água em quantidade e qualidade necessária à atual e às futuras gerações, utilizar os recursos hídricos de forma integrada e racional, e prevenir contra eventos hidrológicos críticos de origem natural ou antrópica (Brasil, 1997). Em função das grandes dimensões, as bacias localizadas no estado de Rondônia são frequentemente fragmentadas em sub-bacias e estas em microbacias, com o intuito de coletar dados mais detalhados da paisagem e aumentar a eficiência do planejamento e gestão dos recursos naturais (Cavalheiro \& Vendruscolo, 2019).

A microbacia do rio Águas Claras pertence a bacia do rio Guaporé e sub-bacia do rio Corumbiara, e tem elevada importância socioeconômica e ambiental. Esta microbacia contém 54 estabelecimentos agropecuários privados (INCRA, 2019) localizados em uma região com o agronegócio em franca expansão (Pereira \& Kahil, 2010), e forma um dos tributários do rio Guaporé, reconhecido por servir como corredor ecológico que conecta a Amazônia ao Pantanal Mato-Grossense (GuarimNeto, Guarim, \& Nascimento, 2010). Entretanto, existe uma escassez de informações na literatura sobre as características da paisagem, para se identificar as potencialidades e limitações dos recursos naturais, e assim, planejar adequadamente sua gestão em busca do desenvolvimento sustentável.

As principais características da paisagem na microbacia estão associadas às informações geométricas, topográficas e hidrográficas, como pode ser observado nos trabalhos realizados nas microbacias dos rios Enganado (Moreto, et al., 2019), Mutum (Souza, et al., 2021), Gavião (Donegá, et al., 2021) e Tamarupá (Vendruscolo, et al., 2021). As geotecnologias permitem a aquisição destas informações em tempo relativamente curto e com baixo custo financeiro (Soares, et al., 2019), e interpretações sobre o nível de suscetibilidade a inundação, potencial agropecuário, disponibilidade de recursos hídricos, aptidão à mecanização agrícola, suscetibilidade a propagação de incêndios, e práticas de manejo mais adequadas para a conservação do solo e da água (Silva, et al., 2021). 
Em face ao exposto, o presente trabalho tem como objetivo utilizar geotecnologias para gerar informações geométricas, topográficas e hidrográficas da microbacia do rio Águas Claras, com o intuito de auxiliar no planejamento e gestão de seus recursos naturais.

\section{Metodologia}

\subsection{Localização e características gerais da área de estudo}

A microbacia do rio Águas Claras está inserida na sub-bacia do rio Corumbiara, e abrange os municípios de Cerejeiras $(99,49 \%)$ e Corumbiara $(0,51 \%)$ (Figura 1). Esta região tem clima classificado como tipo Monção, temperaturas médias entre 24 e $26^{\circ} \mathrm{C}$ (Alvares, et al., 2014) e precipitação média anual de 1.728,9 a 1.843,7 mm, concentrada principalmente nos meses de novembro a março (Franca, 2015).

Figura 1. Localização da microbacia do rio Águas Claras, Amazônia Ocidental, Brasil.
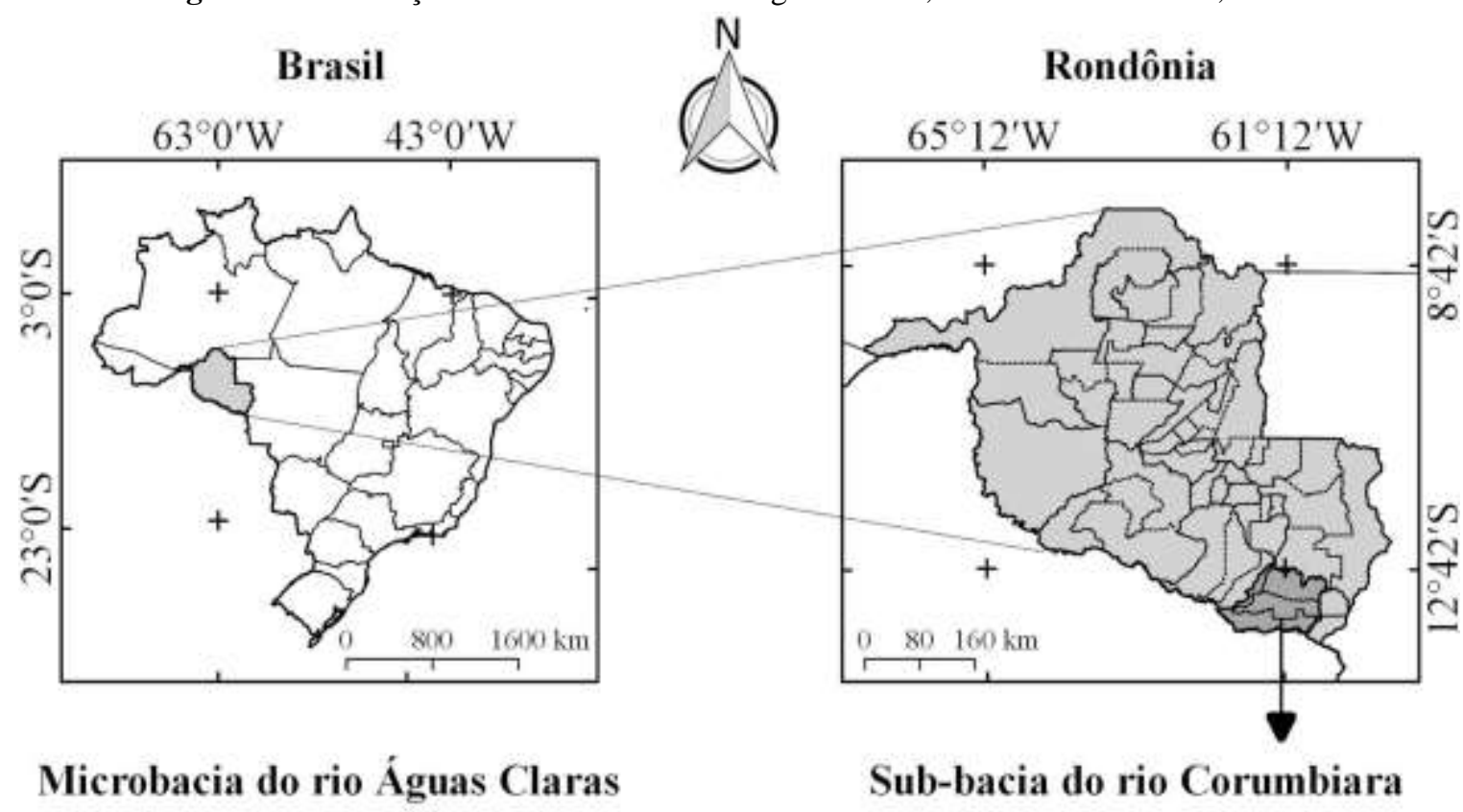

Sub-bacia do rio Corumbiara
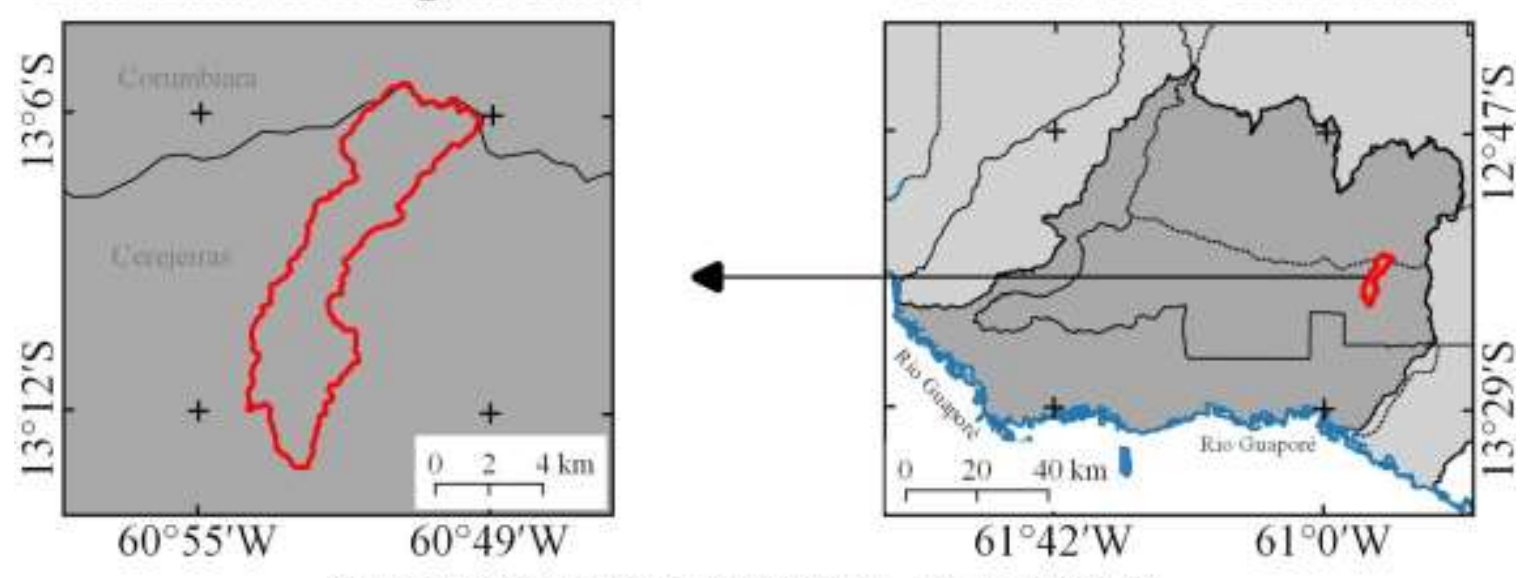

Sistema de Coordenadas Geográficas - Datum WGS 84

Fonte: Autores.

\subsection{Parâmetros da paisagem}

As características da paisagem estão agrupadas em 3 classes: 1) Geométricas: área, perímetro, fator de forma, índice de circularidade e coeficiente de compacidade; 2) Topográficas: altitudes (mínima, média e máxima) e declividade; e 3) 
Hidrográficas: padrão da rede de drenagem, ordem dos rios, densidade de nascentes, densidade de drenagem, coeficiente de manutenção, índice de sinuosidade e tempo de concentração. Estas informações foram obtidas por metodologias quantitativas e qualitativas (Pereira, et al., 2018), como o auxílio dos softwares QGIS 2.10.1 (versão Pisa), Google Earth e TrackMaker Free (Versão 13.9.596), imagens altimétricas do satélite ALOS (ASF, 2017), com resolução espacial de 12,5 m, e dados da literatura.

\section{Características geométricas}

Área e perímetro: estas informações foram adquiridas em 3 etapas. Na primeira, delimitou-se o perímetro da microbacia de forma automática com base na imagem altimétrica, utilizando a ferramenta TauDEM nos seguintes passos: Pit Remove $<D 8$ Flow Directions $<$ D8 Contributing Area $-1^{\text {a }}$ versão $<$ Stream Definition By Threshold $<$ Edição do ponto de exutório $<D 8$ Contributing Area - $2^{\mathrm{a}}$ versão. $\mathrm{Na}$ segunda, converteu-se o arquivo matricial para o formato vetorial (ferramenta "poligonizar"), em seguida, o arquivo foi dissolvido (ferramenta "dissolver"), suavizado (ferramenta "simplificar geometria") e ajustado visualmente no software Google Earth, considerando as características da paisagem. Por fim, na terceira etapa, realizaram-se os cálculos para quantificar a área e o perímetro da microbacia, utilizando a ferramenta "calculadora de campo".

Fator de forma, índice de circularidade e coeficiente de compacidade: estes parâmetros foram mensurados com as Equações 1 (Villela \& Mattos, 1975), 2 (Christofoletti, 1980) e 3 (Villela \& Mattos, 1975), em seguida, os resultados foram comparados com dados da literatura (Tabela 1 ).

$$
F=\frac{A}{L^{2}}
$$

(Equação 1)

Onde: $\mathrm{F}$ = fator de forma; $\mathrm{A}=$ área da microbacia $\left(\mathrm{km}^{2}\right) ; \mathrm{L}=$ comprimento do eixo da microbacia $(\mathrm{km})$.

$$
I c=\frac{12,57 \times A}{P^{2}}
$$

Onde: $\mathrm{Ic}=$ índice de circularidade; $\mathrm{A}=$ área da microbacia $\left(\mathrm{km}^{2}\right) ; \mathrm{P}=$ perímetro da microbacia $(\mathrm{km})$.

$$
K c=0,28 \times \frac{P}{\sqrt{A}}
$$

\begin{tabular}{|c|c|c|}
\hline Parâmetro & Limite & Classe \\
\hline \multirow{3}{*}{ Fator de forma ${ }^{1}$} & $<0,50$ & Não sujeito a inundações \\
\hline & $0,50-0,75$ & Tendência média a inundações \\
\hline & $0,76-1,00$ & Sujeito a inundações \\
\hline \multirow{3}{*}{ Índice de circularidade ${ }^{2}$} & $<0,51$ & Forma alongada \\
\hline & $0,51-0,75$ & Forma intermediária \\
\hline & $0,76-1,00$ & Forma circular \\
\hline \multirow{3}{*}{ Coeficiente de compacidade ${ }^{1}$} & $1,00-1,25$ & Alta propensão a inundações \\
\hline & $1,26-1,50$ & Tendência média a inundações \\
\hline & $>1,50$ & Não sujeito a inundações \\
\hline
\end{tabular}

Onde: $\mathrm{Kc}=$ coeficiente de compacidade; $\mathrm{A}=$ área da microbacia $\left(\mathrm{km}^{2}\right) ; \mathrm{P}=$ perímetro da microbacia $(\mathrm{km})$.

Tabela 1. Classificação dos parâmetros geométricos: fator de forma, índice de circularidade e coeficiente de compacidade.

${ }^{1}$ Lima Júnior, et al. (2012); ${ }^{2}$ Silva (2012). 


\section{Características topográficas}

Altitude e declividade: as altitudes mínima e máxima foram obtidas diretamente da imagem altimétrica, e a altitude média foi mensurada com a ferramenta "estatística por zona". A declividade foi mensurada com base na imagem altimétrica, utilizando a ferramenta "modelo digital de elevação". Em seguida, a declividade foi classificada para identificação do relevo, e obtenção de informações a respeito da influência na propagação de incêndios e aptidão à mecanização agrícola (Tabela 2).

Tabela 2. Classificação da declividade quanto ao relevo, influencia a propagação de incêndios e aptidão à mecanização agrícola.

\begin{tabular}{|c|c|c|}
\hline Parâmetro & Declividade (\%) & Classe \\
\hline \multirow{6}{*}{ Relevo $^{1}$} & $0-3$ & Plano \\
\hline & $3-8$ & Suave ondulado \\
\hline & $8-20$ & Ondulado \\
\hline & $20-45$ & Forte ondulado \\
\hline & $45-75$ & Montanhoso \\
\hline & $>75$ & Escarpado \\
\hline \multirow{5}{*}{ Influência a propagação de incêndios ${ }^{2}$} & $\leq 15$ & Baixa \\
\hline & $16-25$ & Moderada \\
\hline & $26-35$ & Alta \\
\hline & $36-45$ & Muito alta \\
\hline & $>45$ & Extremamente alta \\
\hline \multirow{5}{*}{ Aptidão à mecanização agrícola ${ }^{3}$} & $0-5,0$ & Extremamente apta \\
\hline & $5,1-10,0$ & Muito apta \\
\hline & $10,1-15,0$ & Apta \\
\hline & $15,1-20,0$ & Moderadamente apta \\
\hline & $>20,0$ & Não apta \\
\hline
\end{tabular}

${ }^{1}$ Santos, et al. (2013); ${ }^{2}$ Ribeiro, Formiga e Marcuzzo (2008); ${ }^{3}$ Höfig e Araújo-Júnior (2015).

\section{Características hidrográficas}

Padrão da rede de drenagem: este parâmetro foi identificado por meio de uma comparação visual entre a rede de drenagem da microbacia e os principais padrões de redes de drenagem, disponibilizados por Parvis (1950). Para a elaboração da rede de drenagem da microbacia foram utilizadas 3 etapas: 1) Elaboração dos rios por meio de trilhas no software Google Earth, ferramenta "adicionar caminho"; 2) União das trilhas em formato KML (Keyhole Markup Language), no software TrackMaker Free, com a ferramenta "lápis"; e 3) Conversão do formato KML para o formato Shapefile (SHP), no software QGIS.

Ordem dos rios: foi realizado automaticamente com a ferramenta "strahler". Nesta classificação, os rios de $1^{\text {a }}$ ordem se originam nas nascentes, os rios de $2^{\mathrm{a}}$ ordem se formam pelo encontro de dois rios de $1^{\mathrm{a}}$ ordem, os rios de $3^{\mathrm{a}}$ ordem se formam pelo encontro de dois rios de $2^{\mathrm{a}}$ ordem, e assim sucessivamente.

Densidade de nascentes, densidade de drenagem e coeficiente de manutenção: parâmetros mensurados com as Equações 4 (Santos, et al., 2012), 5 (Horton, 1932), 6 (Santos, et al., 2012):

$$
D n=\frac{N}{A}
$$

Onde: $\mathrm{Dn}=$ densidade de nascentes $\left(\right.$ nascentes $\left.\mathrm{km}^{-2}\right) ; \mathrm{N}=$ número de nascentes; $\mathrm{A}=$ área da microbacia $\left(\mathrm{km}^{2}\right)$. 


$$
D d=\frac{L}{A}
$$

Onde: $\mathrm{Dd}=$ densidade de drenagem $\left(\mathrm{km} \mathrm{km}^{-2}\right) ; \mathrm{L}=$ comprimento da rede de drenagem $(\mathrm{km}) ; \mathrm{A}=$ área da microbacia $\left(\mathrm{km}^{2}\right)$.

$$
C m=\frac{1}{D d} \times 1000
$$

Onde: $\mathrm{Cm}=$ coeficiente e manutenção $\left(\mathrm{m}^{2} \mathrm{~m}^{-1}\right) ; \mathrm{Dd}=$ densidade de drenagem $\left(\mathrm{km} \mathrm{km}^{-2}\right)$.

Índice de sinuosidade e tempo de concentração: parâmetros mensurados com as Equações 7 (Villela \& Mattos, 1975) e 8 (Kirpich, 1940, apud Targa, et al., 2012).

$$
\text { Is }=\frac{L-D v}{L} \times 100
$$

Onde: Is = índice de sinuosidade $(\%) ; \mathrm{L}=$ comprimento do canal principal $(\mathrm{km}) ; \mathrm{Dv}=$ distância vetorial do canal principal $(\mathrm{km})$.

$$
T_{C}=57 \times\left(\frac{L^{3}}{H}\right)^{0,385}
$$

Onde: $\mathrm{Tc}=$ tempo de concentração (minutos); $\mathrm{L}=$ comprimento do talvegue principal $(\mathrm{km}) ; \mathrm{H}=$ desnível entre a parte mais elevada e a seção de controle (m).

Em seguida, compararam-se os valores dos parâmetros ordem dos rios, densidade de nascentes, densidade de drenagem e índice de sinuosidade com dados literatura (Tabela 3), para facilitar a interpretação dos resultados. 
Tabela 3. Classificação de parâmetros hidrográficos.

\begin{tabular}{|c|c|c|c|}
\hline Parâmetro & Unidade & Limite & Classe \\
\hline \multirow{3}{*}{ Ordem dos rios ${ }^{1}$} & \multirow{3}{*}{ Unidades } & $1-3$ & Riachos pequenos \\
\hline & & $4-6$ & Riachos médios \\
\hline & & $>6$ & Rios grandes \\
\hline \multirow{4}{*}{ Ordem dos rios $^{2}$} & \multirow{4}{*}{ Unidades } & 1 & Improvável habitat de peixes \\
\hline & & 2 & Baixas condições para habitação \\
\hline & & 3 & Moderadas condições para habitação \\
\hline & & $\geq 4$ & Elevadas condições para habitação \\
\hline \multirow{4}{*}{ Densidade de nascentes ${ }^{3}$} & \multirow{4}{*}{ Nascentes $\mathrm{km}^{-2}$} & $<3$ & Baixa \\
\hline & & $3-7$ & Média \\
\hline & & $7-15$ & Alta \\
\hline & & $>15$ & Muito alta \\
\hline \multirow{4}{*}{ Densidade de drenagem ${ }^{4}$} & \multirow{4}{*}{$\mathrm{km} \mathrm{km}^{-2}$} & $<0,50$ & Baixa \\
\hline & & $0,50-2,00$ & Média \\
\hline & & $2,00-3,50$ & Alta \\
\hline & & $>3,50$ & Muito alta \\
\hline \multirow{5}{*}{ Índice de sinuosidade ${ }^{5}$} & \multirow{5}{*}{$\%$} & $<20$ & Muito reto \\
\hline & & $20-29$ & Reto \\
\hline & & $30-39$ & Divagante \\
\hline & & $40-50$ & Sinuoso \\
\hline & & $>50$ & Muito sinuoso \\
\hline
\end{tabular}

${ }^{1}$ Vannote, et al. (1980); ${ }^{2}$ Adaptado de Fairfull e Witheridge (2003); ${ }^{3}$ Lollo (1995); ${ }^{4}$ Beltrame (1994); ${ }^{5}$ Romero, Formiga e Marcuzzo (2017).

\section{Elaboração dos mapas}

Para facilitar a análise espacial dos dados foram elaborados mapas de altitude, relevo, rede e ordem de drenagem, e distribuição espacial das nascentes.

\section{Resultados e Discussão}

\subsection{Características geométricas}

A microbacia do rio Águas Claras tem área de $39,27 \mathrm{~km}^{2}$, perímetro de 43,25 km, fator de forma de 0,13, índice de circularidade de 0,26 e coeficiente de compacidade de 1,93, denotando forma alongada e baixa suscetibilidade a inundações, do ponto de vista geométrico (Tabela 1). A microbacia de forma alongada tem menor risco de inundação em comparação a uma microbacia de forma circular e área equivalente por duas razões: têm menor probabilidade de precipitações abrangerem toda a sua área simultaneamente e apresenta os tributários distribuídos em pontos mais distantes ao longo do rio principal (Villela \& Mattos, 1975).

\section{Características topográficas}

Os valores de altitude variam de 227 a 446 m, com valor médio de 291 m (Figura 2), e amplitude altimétrica de 219 m. A altitude afeta a temperatura, precipitação e evaporação (Villela \& Mattos, 1975), portanto, é um fator influente quanto a seleção de ambientes aptos para cultivos de espécies de interesse econômico (Figueiredo, et al., 2015). Em face ao exposto, constatam-se na literatura várias espécies que podem ser encontradas na faixa de altitude da microbacia e se estendem em um amplo leque de mercado, que incluem frutíferas como abacate (Persea americana), banana (Musa sp.), goiaba (Psidium 
guajava) e laranja (Citrus sinensis), hortaliças como abóbora-cheirosa (Cucurbita moschata), cará (Dioscorea alata) e taioba (Xanthosoma sagittifolium), e espécies agrícolas convencionais como arroz (Oryza sativa), feijão (Phaseolus vulgaris), milho (Zea mays) e soja (Glycine max) (Bourke, 2010).

A declividade da paisagem varia de 0 a 72\%. Assim, constata-se que a região tem relevos planos à montanhosos, com predominância das classes suave ondulado (47,62\%) e ondulado (22,82\%) (Figura 3), e 87,32\% da área total considerada de baixa influência na propagação de incêndios e apta a extremamente apta a mecanização agrícola (Tabela 2). Estas características associadas a ampla gama de espécies de interesse econômico, confirma o elevado potencial para o desenvolvimento de sistemas agropecuários na microbacia do rio Águas Claras. Contudo, é necessário adotar práticas de manejo conservacionista do solo e da água, principalmente para as áreas mais declivosas.

O aumento da declividade potencializa os riscos de perda de solo por erosão hídrica, ocasionando problemas relacionados à redução da fertilidade do solo onde está ocorrendo a erosão, assim como o assoreamento e a poluição dos recursos hídricos devido ao acúmulo de sedimentos provenientes das cotas mais altas (Guerra, 2015). As práticas de manejo mais recomendadas para mitigar os riscos podem ser de caráter edáfico, vegetativo e mecânico, e visam melhorar ou manter a fertilidade do solo, reduzir o desprendimento e arraste das partículas de solo, por meio da proteção do solo contra a ação direta das gotas de chuva, e formar barreiras físicas que reduzem o escoamento superficial, favorecendo a infiltração de água (Bertoni \& Lombardi Neto, 2014). Como exemplo de práticas de caráter edáfico têm-se o ajustamento a capacidade de uso, eliminação ou controle das queimadas, rotação de culturas, adubação e calagem, de caráter vegetativo têm-se adubação verde e cultivo em faixas, e de caráter mecânico têm-se plantio em nível e terraceamento (Pacheco, 1980). 
Research, Society and Development, v. 10, n. 3, e21110313363, 2021

(CC BY 4.0) | ISSN 2525-3409 | DOI: http://dx.doi.org/10.33448/rsd-v10i3.13363

Figura 2. Altitude da microbacia do rio Águas Claras, Amazônia Ocidental, Brasil.

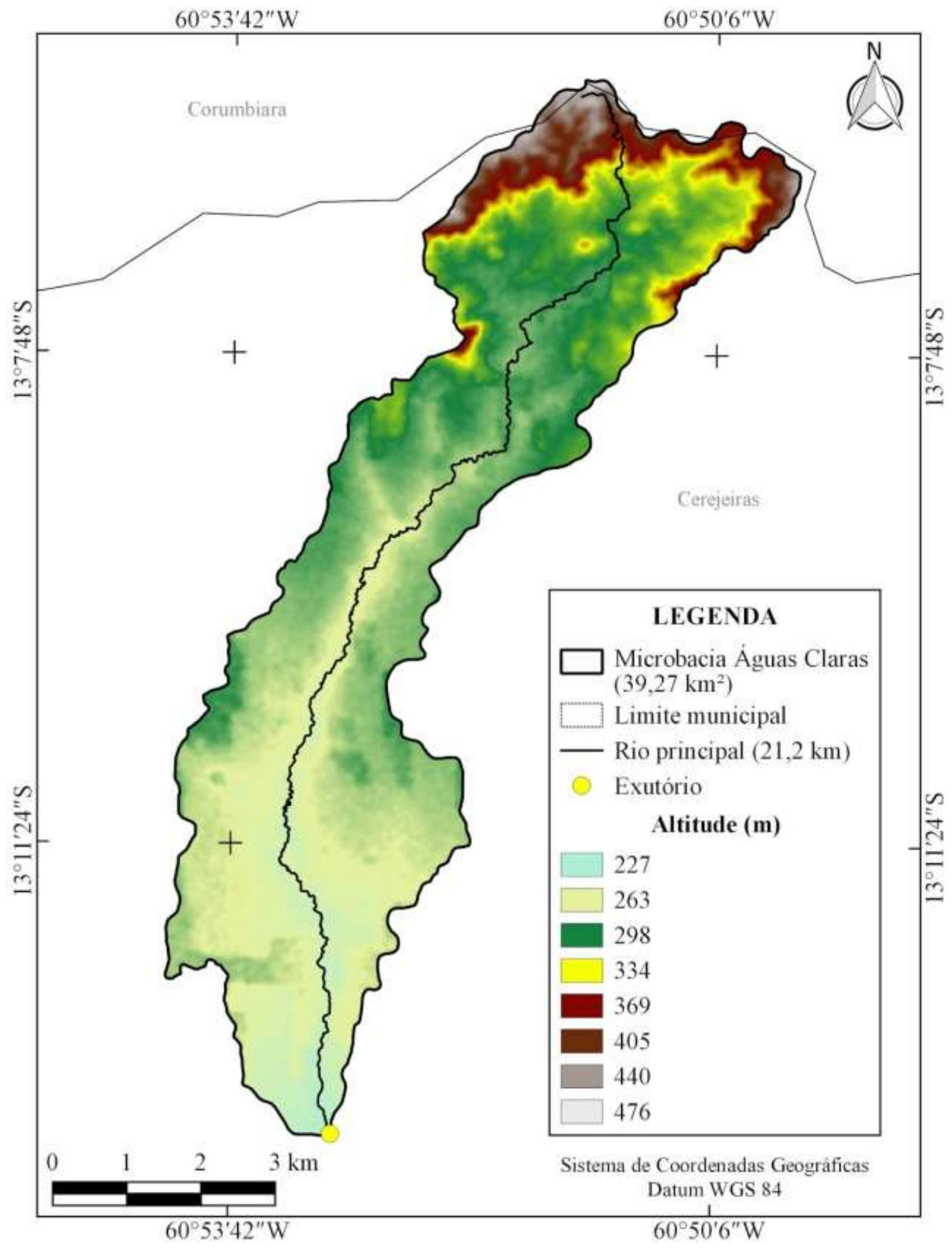

Fonte: Autores. 
Research, Society and Development, v. 10, n. 3, e21110313363, 2021

(CC BY 4.0) | ISSN 2525-3409 | DOI: http://dx.doi.org/10.33448/rsd-v10i3.13363

Figura 3. Relevo da microbacia do rio Águas Claras, Amazônia Ocidental, Brasil.

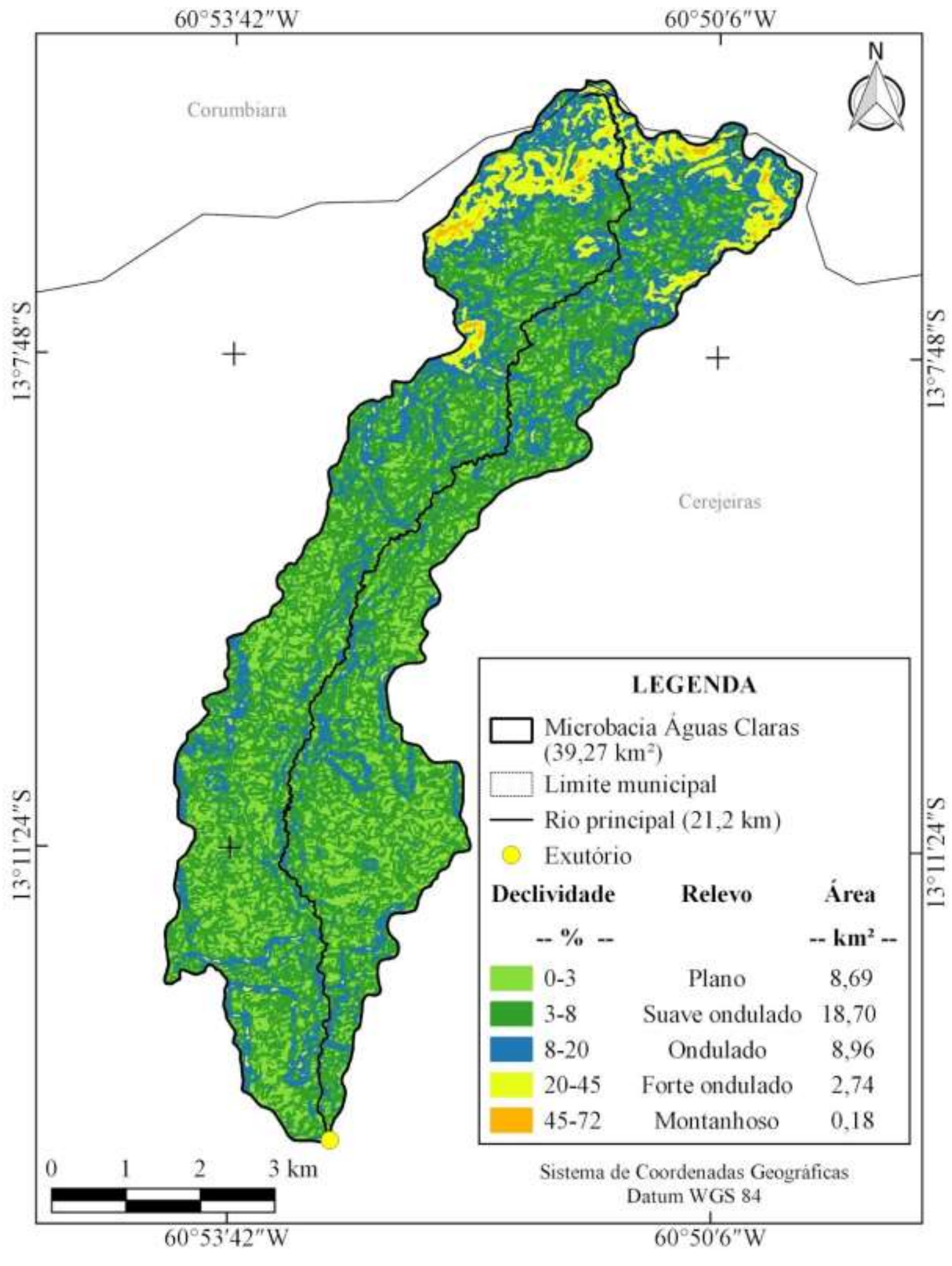

Fonte: Autores. 


\section{Características hidrográficas}

A microbacia do rio Águas Claras tem rede de drenagem de 107,14 km, padrão de drenagem dendrítica, rios de $6^{\mathrm{a}}$ ordem (Figura 4), 8,51 nascentes $\mathrm{km}^{-2}$ (Figura 5), densidade de drenagem de 2,73 km km-2, coeficiente de manutenção de $366,5 \mathrm{~m}^{2} \mathrm{~m}^{-1}$, índice de sinuosidade de 32,55\% e tempo de concentração de $4,06 \mathrm{~h}$.

O padrão de drenagem dendrítico é conhecido como arborescente em função de sua semelhança com os galhos de uma árvore, e desenvolve-se em rochas com resistência uniforme ou em rochas estratificadas horizontais (Cunha, 2015). Esse tipo de padrão é muito comum na região do rio Guaporé, e também foi constatado por Vendruscolo et al. (2020) na microbacia Alto Rio Escondido, Moreto et al. (2019) na microbacia do rio Enganado, e Pacheco et al. (2020) na microbacia do rio São Jorge.

A presença de rios de $6^{a}$ ordem confirma a presença de um rio com grande porte e com elevada condição para habitação de peixes (Tabela 3). Esse resultado corrobora com dados do Instituto Brasileiro de Geografia e Estatística (IBGE), o qual confirma o desenvolvimento de atividades de piscicultura no município de Cerejeiras/RO desde o ano de 2013 (Tabela 4). As principais espécies que conquistaram mercado foram tambaqui, jatuarana e pintado, logo, também se constata o potencial econômico para a produção destas espécies na microbacia.

Tabela 4. Produção de peixes no município de Cerejeiras/RO, no período de 2013 a 2019.

\begin{tabular}{cccccccc}
\hline & \multicolumn{7}{c}{ Ano } \\
\cline { 2 - 7 } Produto & $\mathbf{2 0 1 3}$ & $\mathbf{2 0 1 4}$ & $\mathbf{2 0 1 5}$ & $\mathbf{2 0 1 6}$ & $\mathbf{2 0 1 7}$ & $\mathbf{2 0 1 8}$ & $\mathbf{2 0 1 9}$ \\
& & & & & & & \\
& & & & & & & \\
& & & & & & & \\
Tambaqui & 44,00 & 198,08 & 168,26 & 57,49 & 62,55 & 63,64 & 68,74 \\
Jatuarana & 0,00 & 0,00 & 13,11 & 5,02 & 5,38 & 5,48 & 5,34 \\
Pintado* & 6,00 & 6,00 & 10,93 & 3,67 & 3,73 & 4,40 & 3,99 \\
Pacu e patinga & 2,00 & 2,00 & 6,56 & 2,47 & 2,51 & 2,90 & 3,12 \\
Pirarucu & 0,00 & 34,96 & 19,67 & 0,15 & 0,04 & 0,23 & 0,21 \\
Piauçu & 5,00 & 0,00 & 0,00 & 0,00 & 0,00 & 0,00 & 0,00 \\
\hline Total & $\mathbf{5 7 , 0 0}$ & $\mathbf{2 4 1 , 0 4}$ & $\mathbf{2 1 8 , 5 2}$ & $\mathbf{6 8 , 8 0}$ & $\mathbf{7 4 , 2 0}$ & $\mathbf{7 6 , 6 4}$ & $\mathbf{8 1 , 4 0}$ \\
\hline
\end{tabular}

*Cachara, cachapira, pintachara e surubim. Fonte: IBGE (2021).

As densidades de nascentes da drenagem são altas (Tabela 3), denotando elevada capacidade para gerar novos cursos d'água e alto potencial hídrico para o desenvolvimento de atividades agropecuárias. As nascentes são as principais fontes de água para a manutenção dos igarapés e rios, de modo que a alta densidade de nascentes, como a observada no presente estudo, tende a reduzir a suscetibilidade a escassez hídrica durante o período de estiagem, principalmente na região da cabeceira.

É importante salientar que as florestas nativas desempenham papéis eco-hidrológicos distintos em função de sua localização no relevo, nos topos dos morros para abastecimento do lençol freático, nas encostas para contenção de processos erosivos e nas zonas ripárias para manutenção da qualidade da água (Tambosi, et al., 2015). Logo, o desmatamento excessivo pode comprometer os recursos hídricos da região, mesmo apresentando alta densidade de drenagem, sendo recomendado uma análise espacial da cobertura florestal nativa para se identificar as áreas prioritárias para conservação e recuperação. 
Figura 4. Rede de drenagem e ordem dos rios na microbacia do rio Águas Claras, Amazônia Ocidental, Brasil.

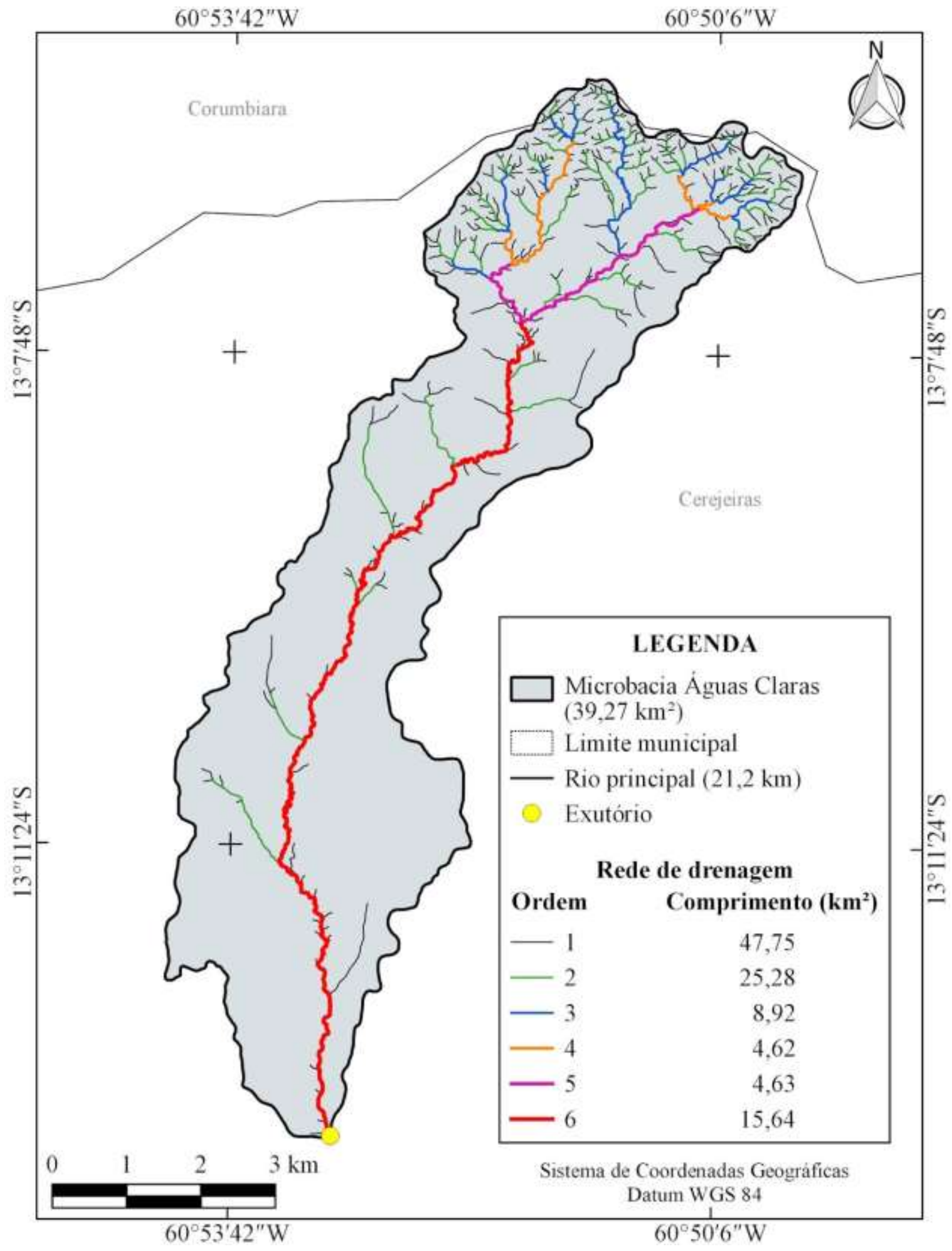

Fonte: Autores. 
Figura 5. Distribuição espacial das nascentes na microbacia do rio Águas Claras, Amazônia Ocidental, Brasil.

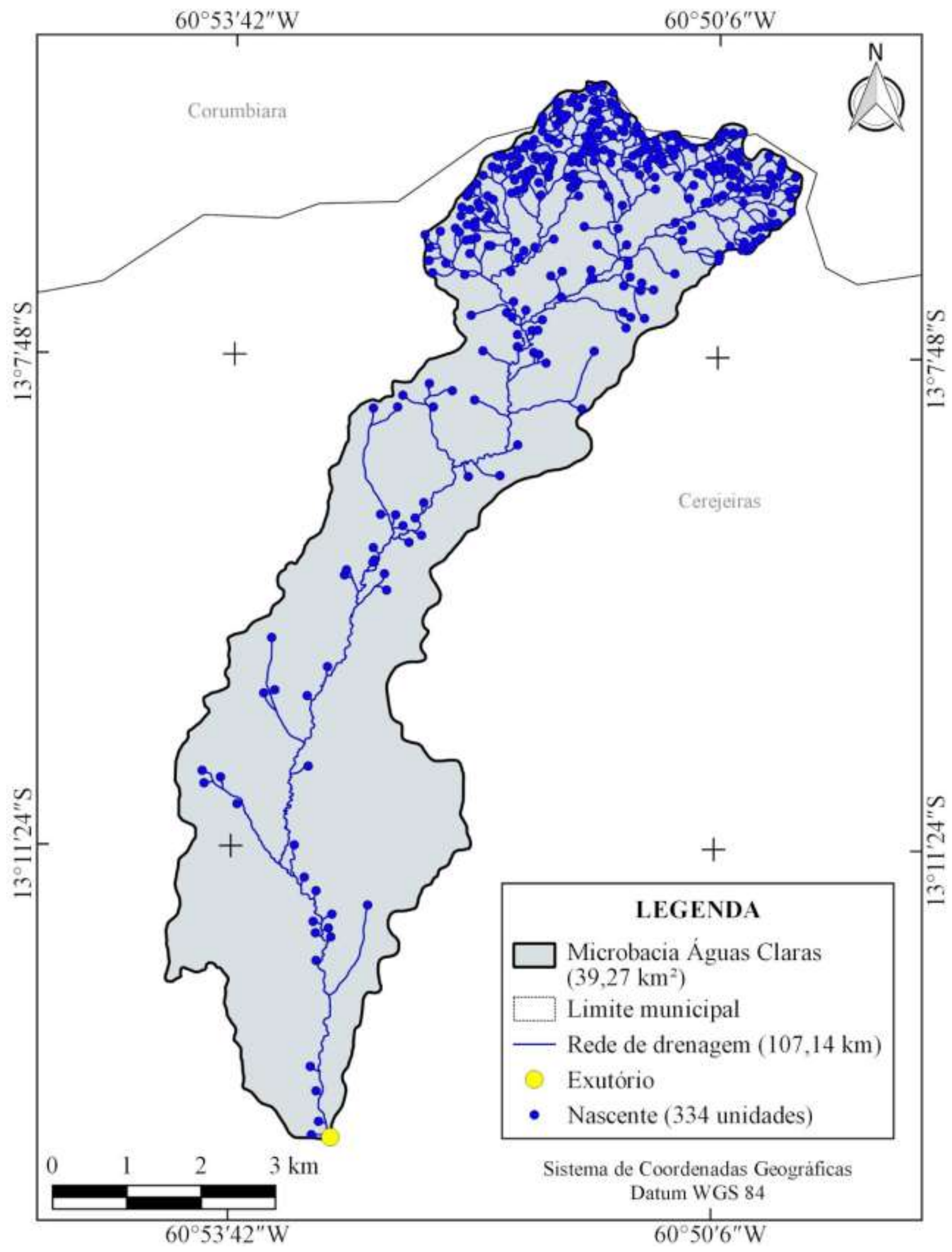

Fonte: Autores. 
O coeficiente de manutenção $\left(366,5 \mathrm{~m}^{2} \mathrm{~m}^{-1}\right)$ é considerado baixo quando comparado com os valores constatados nas microbacias dos rios Mutum (499,4 $\mathrm{m}^{2} \mathrm{~m}^{-1}$ ) (Souza, et al., 2021), Jacuri (1.102,9 $\mathrm{m}^{2} \mathrm{~m}^{-1}$ ) (Panza, et al., 2020) e Gavião (1.250,00 $\mathrm{m}^{2} \mathrm{~m}^{-1}$ ) (Donegá, et al., 2021). Em face ao exposto, verifica-se que é necessário menor quantidade de área para manutenção dos recursos hídricos na microbacia do rio Águas Claras, em relação às demais microbacias.

O rio principal da microbacia tem um canal divagante (Tabela 3), ou seja, classe intermediária entre as classes de canal reto e sinuoso (Ferrari, et al., 2013). O índice de sinuosidade influencia a velocidade do escoamento, sendo observado aumento da velocidade com a redução do índice, devido a menor quantidade de barreiras físicas, logo, existe maior influência nas enchentes a jusante da microbacia (Brubacher, Oliveira \& Guasselli, 2011). Assim, infere-se que a região tem uma velocidade de fluxo hídrico de $5,22 \mathrm{~km} \mathrm{~h}^{-1}$, considerada intermediária, por ser inferior à verificada na microbacia Alto Rio Escondido (5,56 $\left.\mathrm{km} \mathrm{h}^{-1}\right)$ (Vendruscolo, et al., 2020) e superior à constatada na microbacia do rio Mutum (3,66 $\left.\mathrm{km} \mathrm{h}^{-1}\right)$ (Souza, et al., 2021).

Conhecer o tempo de concentração é importante para compreender o comportamento do escoamento superficial na bacia hidrográfica, o qual está associado a diversos fenômenos como: erosão do solo, transporte de sedimentos, enxurradas, ocorrência de enchentes, entre outras. Tais fenômenos podem trazer prejuízos socioeconômicos e ambientais no meio em que ocorrem (Mamédio, Castro \& Corseuil, 2018).

O tempo de concentração corresponde ao tempo necessário para que o escoamento se desloque do ponto mais distante hidraulicamente na bacia hidrográfica até a saída (Kirpich, 1940 apud Fang, et al., 2008), denominada de exutório, e denota a velocidade com que o divisor de águas responde a eventos de precipitação (Pavlovic \& Moglen, 2008). Na microbacia do rio Águas Claras o tempo de concentração é de $4,06 \mathrm{~h}$, tempo superior ao encontrado na microbacia do rio Gavião $(2,74 \mathrm{~h})$ (Donegá, et al., 2021). A diferença de tempo está relacionada com o comprimento dos canais, o rio Águas Claras tem um canal mais longo, aproximadamente $21,2 \mathrm{~km}$, enquanto o rio Gavião tem um canal mais curto, em torno de 11,32 km.

\section{Conclusão}

A microbacia do rio Águas Claras tem área de $39,27 \mathrm{~km}^{2}$, perímetro de $43,25 \mathrm{~km}$, forma alongada, baixa suscetibilidade a inundações, altitudes entre 227 e $446 \mathrm{~m}$, predominância de relevo suave ondulado, padrão dendrítico de $6^{\mathrm{a}}$ ordem, alta densidade de nascentes, alta densidade de drenagem, coeficiente de manutenção de $366,5 \mathrm{~m}^{2} \mathrm{~m}^{-1}$, canal principal divagante e tempo de concentração de $4,06 \mathrm{~h}$.

As características da paisagem confirmam o elevado potencial para o desenvolvimento de atividades agropecuárias, inclusive para o uso de maquinários agrícolas em $87,32 \%$ da microbacia, contudo, são necessários planejamentos que considerem as práticas de manejo conservacionista do solo e da água para mitigar os impactos destas atividades, e assim, conservar os recursos naturais.

A manutenção da qualidade e disponibilidade hídrica depende de quantidades adequadas de floresta nativa em cada porção do relevo, portanto, recomendam-se estudos sobre a distribuição espacial da cobertura do solo da microbacia do rio Águas Claras, para complementar as informações fornecidas neste trabalho, e assim, auxiliar no planejamento e gestão dos recursos naturais.

\section{Referências}

Alvares, C. A, Stape, J. L., Sentelhas, P. C., Gonçalves, L. M., \& Sparovek, G. (2014). Köppen's climate classification map for Brazil. Meteorologische Zeitschrift, 22(6), 711-728. 10.1127/0941-2948/2013/0507

ASF - Alaska Satellite Facility (2017). Imagem altimétrica. https://www.asf.alaska.edu/ 
Beltrame, A. V. (1994). Diagnóstico do meio ambiente físico de bacias hidrográficas: modelo de aplicação. Florianópolis: Universidade Federal de Santa Catarina.

Bertoni, J., \& Lombardi Neto, F (2014). Conservação do solo. Editora Ícone.

Bourke, R. M. (2010). Altitudinal limits of 230 economic crop species in Papua New Guinea. In: Haberle, S.G., Stevenson, J., \& Prebble, M. (eds). Altered Ecologies: Fire, Climate and Human Influence on Terrestrial Landscapes. Canberra: The Australian National University.

Brasil. (1997). Lei $n^{\circ}$ 9.433, de 8 de janeiro de 1997: Institui a Política Nacional de Recursos Hídricos, cria o Sistema Nacional de Gerenciamento de Recursos Hídricos, regulamenta o inciso XIX do art. 21 da Constituição Federal, e altera o art. $1^{\circ}$ da Lei no 8.001 , de 13 de março de 1990, que modificou a Lei $n^{\circ}$ 7.990, de 28 de dezembro de 1989. www.planalto.gov.br/ccivil_03/leis/L9433.htm

Brubacher, J. P., Oliveira, G. G., \& Guasselli, L. A. Suscetibilidade de enchentes a partir da análise das variáveis morfométricas na bacia hidrográfica do rio dos Sinos/RS. XV Simpósio Brasileiro De Sensoriamento Remoto, 2011. Anais... São José dos Campos: INPE.

Cavalheiro, W. C. S., \& Vendruscolo, J. (2019). Importância de estudos em bacias hidrográficas para o manejo sustentável dos recursos hídricos em Rondônia. Revista Geográfica Venezolana, especial, 256-264.

Christofoletti, A. (1980). Geomorfologia. (2a ed.), Edgard Blucher.

Cunha, S. B. (2015). Geomorfologia fluvial. In: Guerra, A. J. T., \& Cunha, S. B. Geomorfologia: uma atualização de bases e conceitos. Bertrand Brasil.

Donegá, M. V. B., Souza, T. W. S., Lima, M. M., Panza, M. R., Pacheco, F. M. P., Saraiva, J. G., Cavalheiro, W. C. S., \& Vendruscolo, J. (2021). Hydrogeomorphometric characterization in the Gavião river microbasin, Western Amazon, Brazil. Research, Society and Development, 10(1), 1-14. $10.33448 /$ rsd-v10i1.11844.

Fairfull, S., \& Witheridge, G. (2003). Why do Fish Need to Cross the Road? Fish Passage Requirements for Waterway Crossings. NSW Fisheries.

Fang, X., Thompson, D. B., Cleveland, T. G., Phadhan, P., \& Malla, R. (2008). Time of Concentration Estimated Using Watershed Parameters Determined by Automated and Manual Methods. Journal of Irrigation and Drainage Engineering, 134(2), 202-211. 10.1061/ASCE0733-94372008134:2202

Figueiredo, S. M. M., Venticinque, E. M., Figueiredo, E. O., \& E. Ferreira, E. J. L. (2015). Predição da distribuição de espécies florestais usando variáveis topográficas e de índice de vegetação no leste do Acre, Brasil. Acta Amazonica, 45(2), 167-174.

Ferrari, L. F., Silva, S. F., Santos, A. R., \& Garcia, R. F. (2013) Análise morfométrica da sub-bacia hidrográfica do córrego Horizonte, Alegre, ES. Revista Brasileira de Ciências Agrárias, 8(2), 181-188. 10.5039/agraria.v8i2a1575

Franca, R. R. (2015). Climatologia das chuvas em Rondônia - período 1981-2011. Revista Geografias, 11(1), 44-58. https://periodicos.ufmg.br/index.php/geografias/article/view/13392/10624

Guarim-Neto, G., Guarim, V. L. M. S., \& Nascimento, N. P. O. (2010). Etnobotânica no Pantanal: O Saber Botânico Tradicional Pantaneiro. Flovet, 2, 1-68.

Guerra, A. J. T. (2015). Processos erosivos nas encostas. In: Guerra, A. J. T., \& Cunha, S. B. Geomorfologia: uma atualização de bases e conceitos. Bertrand Brasil.

Höfig, P., \& Araujo-Junior, C. F. (2015). Classes de declividade do terreno e potencial para mecanização no estado do Paraná. Coffee Science, 10(2), 195-203.

Horton, R. E. (1932). Drainage basin characteristics. Transactions, American Geophysical Union, 13(1), 350-361.

INCRA - Instituto Nacional de Colonização e Reforma Agrária (2019). Acervo fundiário. http://acervofundiario.incra.gov.br/acervo/acv.php.

IBGE - Instituto Brasileiro de Geografia e Estatística (2021). Pesquisa da pecuária municipal: produção da aquicultura, por tipo de produto. https://sidra.ibge.gov.br/tabela/3940.

Lima Júnior, J. C., Vieira, W. L., Macêdo, K. G., Souza, S. A., \& Nascimento, F. A. L. (2012). Determinação das características morfométricas da sub-bacia do Riacho Madeira Cortada, Quixelô, CE. VII Congresso Norte-Nordeste de Pesquisa e Inovação. Palmas-TO: Instituto Federal de Educação, Ciência e Tecnologia. p. 1-7.

Lollo, J.A. (1995). O uso da técnica de avaliação do terreno no processo de elaboração do mapeamento geotécnico: sistematização e aplicação na quadrícula de Campinas. São Carlos-SP: Universidade de São Paulo.

Mamédio, F. M. P., Castro, R. N. M., \& Corseuil, C. W. (2018). Tempo de concentração para Bacias Rurais Monitoradas na Região do Planalto Basáltico no Sul do Brasil. REGA, 15, 1-17. 10.21168/rega.v15e1

Moreto, R. F., Mira, S. F., Soares, G. S., Santos Junior, N. R. F., Cavalheiro, W. C. S, Vendruscolo, J., \& Rosa, D. M. (2019). Características geométricas, topográficas e hidrográficas da microbacia do rio Enganado, região sul da Amazônia Ocidental. Revista Geográfica Venezolana, especial, 110-124. http://www.saber.ula.ve/handle/123456789/46159

Pacheco, E. B. (1980). Conservação e manejo do solo. Embrapa.

Pacheco, F. M. P., Vendruscolo, J., Ramos, F. H., Rodrigues, A. A. M., Cavalheiro, W. C. S., Hara, F. A. S., Rocha, K. J., \& Silva, G. N. (2020). Caracterização hidrogeomorfométrica da microbacia do rio São Jorge, Rondônia, Brasil. Brazilian Journal of Development, 6(1), 4219-4236. $10.34117 /$ bjdv6n1-301

Panza, M. R., Donegá, M. V. B., Pacheco, F. M. P., Nagao, E. O., Hara, F. A. S., Cavalheiro, W. C. S., \& Vendruscolo, J. (2020). Características da paisagem para manejo dos recursos naturais na microbacia do Rio Jacuri, Amazônia Ocidental, Brasil. Brazilian Journal of Development, 6(12), 101532-101558. $10.34117 /$ bjdv6n12-592 
Parvis, M. (1950). Drainage pattern significance in airphoto identification of soils and bedrocks. Photogrammetric Engineering, 16, $387-408$.

Pavlovic, S. B., \& Moglen, G. E. (2008). Discretization issues in travel time calculation. Journal of Hydrologic Engineering, 13(2), 71-79. 10.1061/(ASCE)1084-0699(2008)13:2(71)

Pereira, A.S., Shitsuka, D.M., Parreira, F.J., \& Shitsuka, R. (2018). Metodologia da Pesquisa Científica. Santa Maria-RS: Universidade Federal de Santa Maria. https://repositorio.ufsm.br/bitstream/handle/1/15824/Lic_Computacao_Metodologia-Pesquisa-Cientifica.pdf?sequence=1

Pereira, M. F. V., \& Kahil, S. P. (2010). A lógica corporativa do uso do território em Rondônia: o agronegócio da soja na região de Vilhena. CampoTerritório: Revista de Geografia Agrária, 5(10), 288-311.

Ribeiro, L., Koproski, L. P., Stolle, L., Lingnau, C., Soares, R. V., \& Batista, A. C. (2008). Zoneamento de riscos de incêndios florestais para a Fazenda Experimental do Canguiri, Pinhais (PR). Floresta, 38(3), 561-572. 10.5380/rf.v38i3.12430

Romero, V., Formiga, K. T. M., \& Marcuzzo, F. F. N. (2017). Estudo hidromorfológico de bacia hidrográfica urbana em Goiânia/GO. Ciência e Natura, 39(2), 320-340. 10.5902/2179460X26411

Santos, A. M., Targa, M. S., Batista, G. T., \& Dias, N. W. (2012). Análise morfométrica das sub-bacias hidrográficas Perdizes e Fojo no município de Campos do Jordão, SP, Brasil. Revista Ambiente \& Água, 7(3), 195-211. 10.4136/1980-993X

Santos, R. D., Lemos, R. C., Santos, H. G., Ker, J. C., Anjos, L. H. C., \& Shimizu, S. H. (2013). Manual de descrição e coleta de solo no campo. Viçosa-MG: Sociedade Brasileira de Ciência do Solo.

Silva, E. C., Praia, W. M., Santos, A. S., Cardoso, L. A. P., Hara, F. A. S., Cavalheiro, W. C. S., \& Vendruscolo, J. (2021). Características hidrogeomorfométricas da microbacia Três Galhos, Amazônia Ocidental, Brasil. Research, Society and Development, 10(2), 1-17, 2021. 10.33448/rsdv10i2.12408

Silva, Q. D. (2012). Mapeamento geomorfológico da Ilha do Maranhão. Universidade Estadual Paulista.

Soares, G. S., Santos Júnior, N. R. F., Mira, S. F., Moreto, R. F., Cavalheiro, W. C. S., Vendruscolo, J., \& Rosa, D. M. (2019). Uso de plataforma SIG na caracterização morfométrica da microbacia do rio Santa Teresinha, Amazônia Ocidental, Brasil. Revista Geográfica Venezolana, especial, 84-95. http://www.saber.ula.ve/handle/123456789/46157

Souza, T. W. S., Lima, M. M., Saraiva, J. G., Pacheco, F. M. P., Donegá, M. V. B., Panza, M. R., Cavalheiro, W. C. S., \& Vendruscolo, J. (2021). Análise hidrogeomorfométrica da microbacia do rio Mutum: informações para auxiliar o manejo de recursos hídricos na Amazônia Ocidental. Research, Society and Development, 10(2), 1-17. 10.33448/rsd-v10i2.12448

Tambosi, L., Vidal, M. M., Ferraz, S. F. B., \& Metzger, J. P. (2015). Funções eco-hidrológicas das florestas nativas e o Código Florestal. Estudos Avançados, 29(84), 151-162. 10.1590/S0103-40142015000200010

Targa, M. S., Batista, G. T., Diniz, H. D., Dias, N. W., \& Matos, F. C. (2012). Urbanização e escoamento superficial na bacia hidrográfica do Igarapé Tucunduba, Belém, PA, Brasil. Revista Ambiente \& Água, 7(2), 120-142. 10.4136/1980-993X

Vendruscolo, J., Pacheco, F. M. P., Ramos, H. F., Cavalheiro, W. C. S., \& Rodrigues, A. A. M. (2020). Hidrogeomorfometria da microbacia Alto Rio Escondido: informações para auxiliar o manejo dos recursos naturais na Amazônia ocidental. Brazilian Journal of Development, 6(3), 9709-9730. $10.34117 /$ bjdv6n3-011

Vannote, R. L., Minshall, G. W., Cummins, K. W., Sedell, J. R., \& Cushing, C. E. (1980). The river continuum concept. Canadian Journal of Fisheries and Aquatic Sciences, 37, 130-137.

Villela, S. M., \& Mattos, A. (1975). Hidrologia aplicada. McGraw-Hill. 